\title{
Effects of different intensities of exercise on folliculogenesis in mice: Which is better?
}

\author{
Fitri Kurnia Rahayu' ${ }^{1}$, Sri Ratna Dwiningsih ${ }^{2}$, Ashon Sa'adi ${ }^{2}$, Lilik Herawati ${ }^{3}$ \\ ${ }^{1}$ Midwifery Education Program, Faculty of Medicine, Universitas Airlangga, Surabaya; ${ }^{2}$ Department of Obstetrics and Gynecology, Faculty of \\ Medicine, Universitas Airlangga, Dr. Soetomo Hospital, Surabaya; ${ }^{3}$ Department of Physiology, Faculty of Medicine, Universitas Airlangga, \\ Surabaya, Indonesia
}

Objective: Exercise is a risk factor for infertility in women. However, research on the effects of different intensities of exercise on folliculogenesis has not yielded clear results. This study was conducted to analyze the effects of differences in the intensity of exercise on folliculogenesis in mice.

Methods: Nineteen female BALB/c mice (age, 3-4 months; weight, 13-25 g) were randomly divided into four groups: control, mild exercise, moderate exercise, and high-intensity exercise. The mice in the exercise groups engaged in swimming, with additional loads of $3 \%, 6 \%$, or $9 \%$ of body weight, respectively. There were five swimming sessions per week for 4 weeks, with a gradually increasing duration every week. At the end of the treatment, ovarian extraction was carried out and hematoxylin and eosin staining was performed to identify folliculogenesis. Results: There were significant differences in the number of total follicles between the control and moderate-exercise groups $(p=0.036)$ and between the mild- and moderate-exercise groups $(p=0.005)$. The mean number of primary follicles was higher in the moderate-exercise group than in the mild-exercise group ( $p=0.006)$. The mean number of secondary, tertiary, and Graafian follicles did not differ significantly among groups $(p \geq 0.05)$. However, the number of total follicles and follicles in each phase tended to increase after exercise, especially moderate-intensity exercise.

Conclusion: Exercise of different intensities affected the total number of follicles and primary follicles. The number of follicles of each phase tended to increase after exercise. Moderate-intensity exercise had better effects than other intensities of exercise.

Keywords: Exercise; Health; Mice; Ovarian follicle

\section{Introduction}

Over the past few decades, more women have participated in competitive sports and become athletes [1,2]. Exercise has positive effects on the body and improves health in various ways, but it can

Received: July 17, 2020 • Revised: September 3, 2020 • Accepted: September 23, 2020 Corresponding author: Lilik Herawati

Department of Physiology, Faculty of Medicine, Airlangga University, Mayjen Prof. Dr. Moestopo 47, Surabaya, Jawa Timur 60131, Indonesia

Tel: +62-8123181104 Fax: +62-31-5022472 E-mail: lilik_heraw@fk.unair.ac.id

*This research was supported by Faculty of Medicine, Universitas Airlangga, Indonesia.

This is an Open Access article distributed under the terms of the Creative Commons Attribution Non-Commercial License (http://creativecommons.org/licenses/by-nc/4.0/) which permits unrestricted non-commercial use, distribution, and reproduction in any medium, provided the original work is properly cited. also increase the risk of infertility in women [3,4]. Different intensities of physical exercise have different effects on the female reproductive system [3]. The female reproductive system is very sensitive to physiological changes, and $6 \%-79 \%$ of women involved in athletic activity experience menstrual disorders such as amenorrhea [1]. Exercise can increase levels of $\beta$-endorphins and dopamine, which can interfere with gonadotropin-releasing hormone $(\mathrm{GnRH})$ pulses, thereby inhibiting follicle-stimulating hormone (FSH) production $[5,6]$. Exercise also triggers oxidative stress, which results in apoptosis in granulosa cells, including ovarian follicles [7,8]. Both of these mechanisms can cause folliculogenesis disorders, with important implications for female reproductive physiological function, which is closely related to folliculogenesis.

Kelley et al. [9] conducted a 3-week exercise study on mares, in- 
volving running, to identify changes in the number of follicles based on their diameter, and found no significant differences in the number of large follicles. A similar study was performed by Seyed Saadat et al. [4], who reported a decrease in the number of secondary follicles and Graafian follicles, but no significant differences in primary and primordial follicles in mice forced to swim after being placed in water with temperatures of $10^{\circ} \mathrm{C}$ and $23^{\circ} \mathrm{C}$. The effects of differences in the intensity of exercise on folliculogenesis are unknown. The aim of this study was therefore to analyze the effects of exercise of different intensities on folliculogenesis using a histological technique (hematoxylin and eosin [H\&E] staining). Folliculogenesis in this study was observed indirectly, by calculating the total follicle number and the number of each type of follicle. It is hoped that the data obtained from this study could provide insights into the effects of exercise at various intensities on women's reproductive health.

\section{Methods}

This animal study was approved by the Ethics Committee of the Faculty of Medicine, Universitas Airlangga, Indonesia (43/EC/KEPK/ FKUA/2019), and conduct was given to conduct the study at the Faculty of Veterinary Medicine, Universitas Airlangga, Indonesia. This study was a randomized, cross-sectional study with a post-test-only control group design.

\section{Animals and exercise procedure}

The research was conducted at the Faculty of Veterinary Medicine, Universitas Airlangga. In this study, 19 female BALB/c (age, 3-4 months; weight, 13-25 g) were housed under standard laboratory condition (12-hour light/dark cycle) with free access to tap water and chow. The treatment flow is summarized in Figure 1. The mice were randomly divided into four groups: control (no exercise), mild exercise (swimming with an additional load of $3 \%$ of body weight), moderate exercise (swimming with an additional load of $6 \%$ of body weight), high-intensity exercise (swimming with an additional load of $9 \%$ of body weight). The intensities of swimming were determined following the workload levels described by Bompa and Carrera [10]. The choice of different intensities based on the percentage load of body weight was based on the findings reported by Gobatto et al. [11], who showed that, in rats subjected to different intensities of swimming, a $6 \%$ load corresponded to the maximal lactate steady state, while an $8 \%$ load represented higher exercise intensity. This study therefore compared intensities below the anaerobic threshold (3\%), around the anaerobic threshold (6\%), and above the threshold (9\%).

The swimming protocol was adapted from Herawati et al. [12]. We

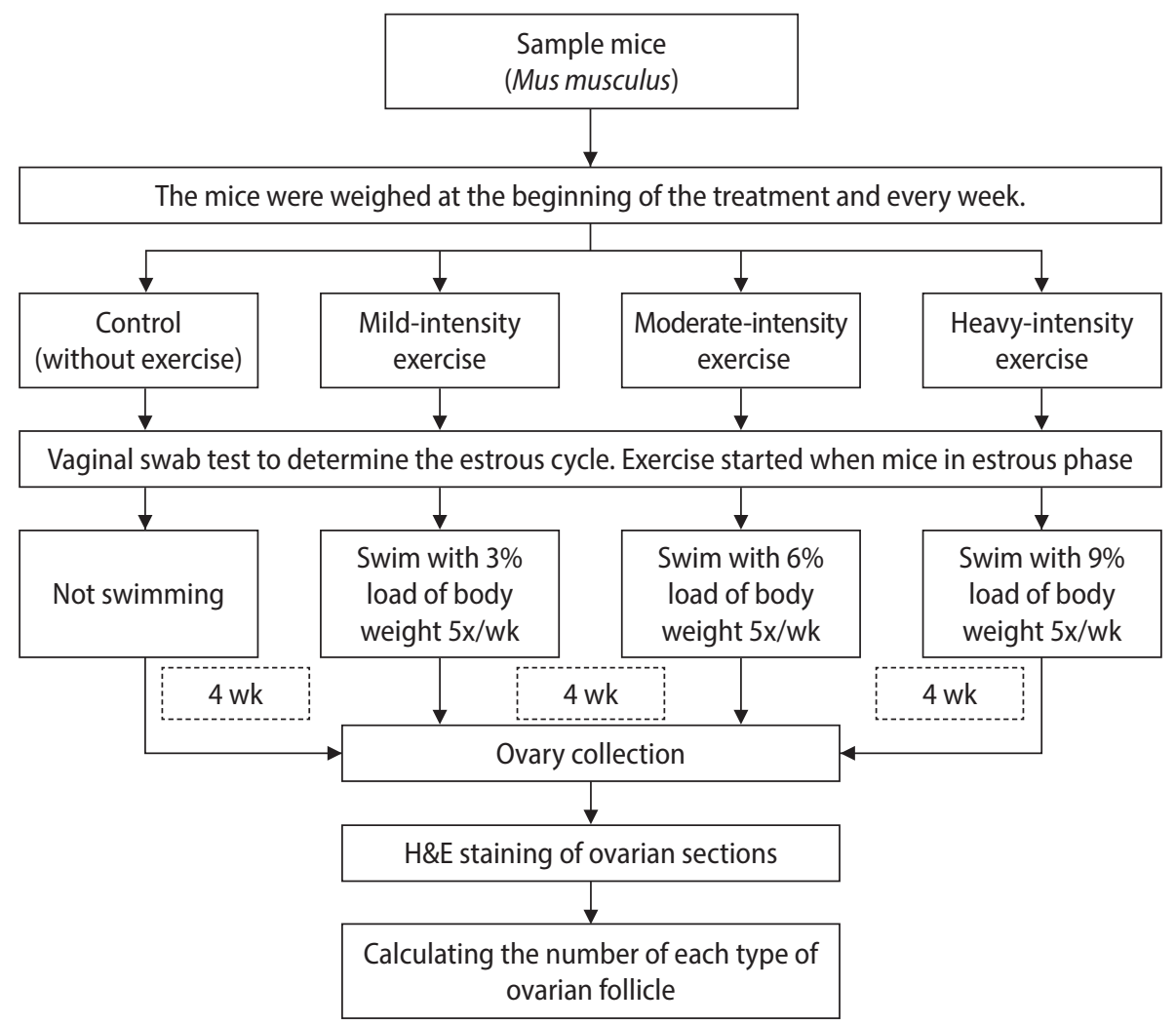

Figure 1. Methodological flowchart of the study. 
used a rectangular polyethylene tank $(50 \mathrm{~cm}$ long $\times 30 \mathrm{~cm}$ deep $\times 25$ $\mathrm{cm}$ wide) with $18-\mathrm{cm}$-deep water at $20^{\circ} \mathrm{C} \pm 5^{\circ} \mathrm{C}$. The swimming sessions each lasted for 3 minutes in the first week and increased gradually in length; the sessions in the second week lasted for 5 minutes, those in the third week lasted for 7 minutes, and those in the final week lasted for 9 minutes a day. Gradual improvement is the principle of exercise, and this design also aimed to avoid death in mice [13]. Treatment was given five times per week (Monday to Friday) for 4 weeks [12]. The swimming treatments in all groups were carried out during the day. To ensure that the mice were aligned in terms of the reproduction phase, all mice started the swimming program when they were in the estrus phase, as seen from the results of vaginal swabs.

At the end of the treatment, the next morning, the mice were sacrificed using $70 \%$ ether anesthesia and the medial part of the abdomen was surgically removed to retrieve the ovary. The ovaries then were processed for histology preparation with $\mathrm{H} \& \mathrm{E}$ staining. Before H\&E staining, the ovaries were embedded in paraffin or wax blocks to enable clean thin-section cutting. A microtome was used to cut the paraffin blocks into approximately 2 - $\mu \mathrm{m}$-thick samples.

\section{Folliculogenesis in the ovary}

Folliculogenesis was observed with a light microscope with $\times 100$ magnification (Figure 2). Folliculogenesis was quantified by calculat- ing the total number of primary, secondary, tertiary, and Graafian follicles, classified based on their morphology, in five visual fields for each preparation. Follicles were classified as primary if they showed a single layer of cuboidal granulosa cells. Secondary follicles possessed more than one layer of granulosa cells with no visible antrum. Tertiary follicles possessed generally only one or two small areas of follicular fluid (antrum). Graafian follicles had a rim of cumulus cells surrounding the oocyte [14]. The follicle calculations were made by two observers (FKR and BAP) and the data were presented as averages for each group.

\section{Statistical analysis}

Data were analyzed using IBM SPSS ver. 21.0 (IBM Corp., Armonk, NY, USA). One-way analysis of variance (ANOVA) was used when the data were normally distributed, and the Kruskal-Wallis test when the data were not normally distributed. Once a significant difference was found, it was confirmed using the post-hoc least significance difference or Mann-Whitney test. The significance level used was $5 \%$.

\section{Results}

\section{Characteristics of subjects}

The body weight of the mice increased during treatment in all groups (Table 1). The highest increase was found in the control group
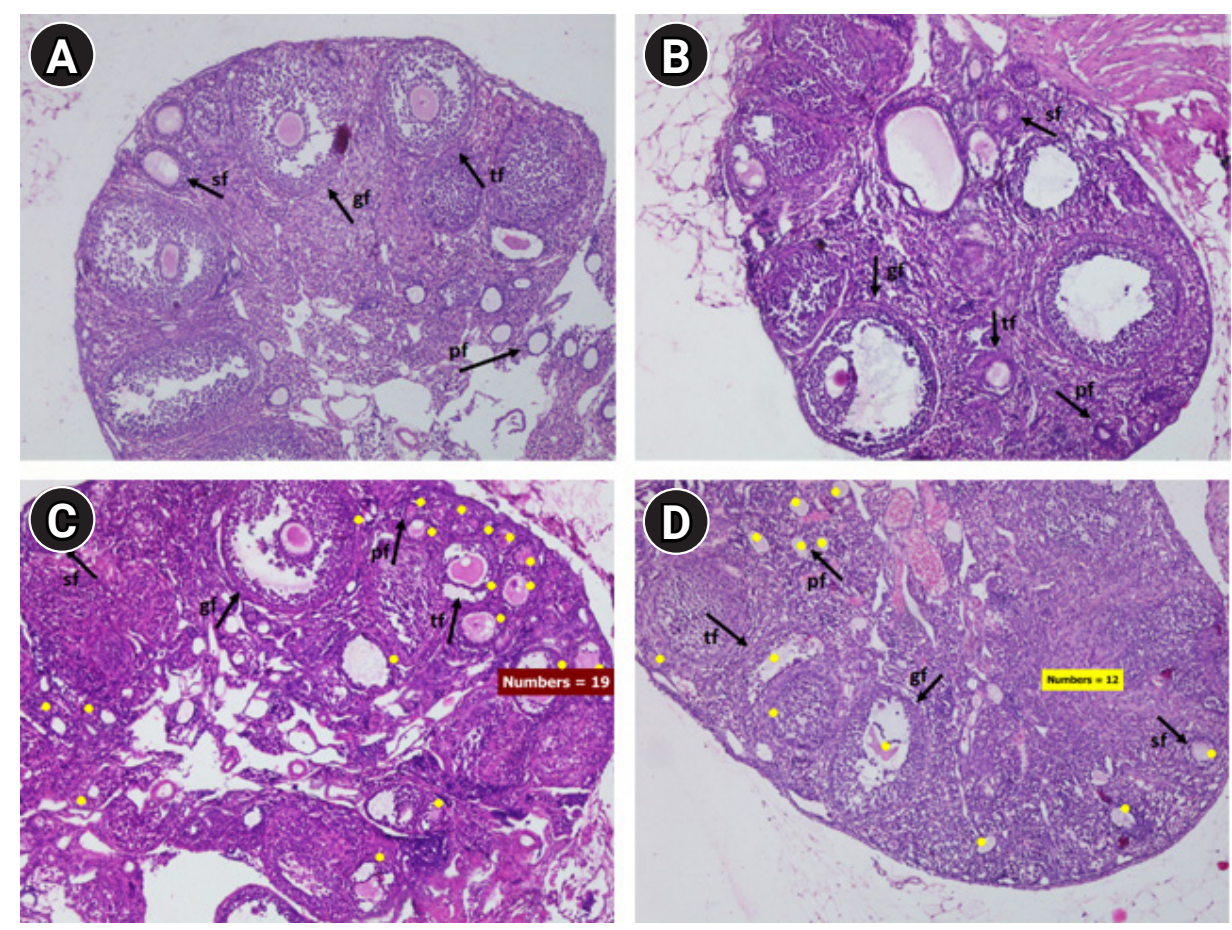

Figure 2. Light photomicrographs of mouse ovaries with H\&E staining $(\times 100)$. (A) Control group, (B) mild-intensity group, (C) moderateintensity group, (D) high-intensity group. Swimming increased the number of ovarian follicles, especially in the moderate-intensity group. sf, secondary follicle; gf, Graafian follicle; tf, tertiary follicle; Pf, primary follicle. Yellow dot, follicle count. 
and the lowest increase was found in the moderate-intensity group. However, according to ANOVA, the body weight increase was not significantly different among the groups ( $p=0.784)$.

\section{Total follicles}

There were significant differences in the number of total follicles between the control group and the moderate-exercise group $(p=0.036)$ and between the mild-exercise group and the moderate-exercise group ( $p=0.005$ ) (Table 2). Compared to the control group, a higher intensity of exercise corresponded to a higher total number of follicles. However, the peak number of total follicles was in the moderate-exercise group (Figure 1).

\section{Primary follicles}

The number of primary follicles differed significantly between the mild-exercise group and the moderate-exercise group ( $p=0.006)$ (Table 2). More intense exercise was associated with a higher number of primary follicles than in the control group. The highest number of primary follicles was in the moderate-exercise group.

\section{Secondary follicles}

The number of secondary follicles was higher in the groups that received exercise training, although there were no significant differences between the control and treatment groups $(p=0.096)$ (Table 2).

\section{Tertiary follicles}

More tertiary follicles were found in the treatment groups, but the difference compared to the control group was not significant

Table 1. Body weight of mice before and after treatment

\begin{tabular}{lccc}
\hline \multirow{2}{*}{ Group } & $\mathrm{n}$ & \multicolumn{2}{c}{ Body weight (g) } \\
\cline { 3 - 4 } & & Before treatment & After treatment \\
\hline Control & 4 & 15.5 & 22.8 \\
Mild-intensity exercise & 4 & 16.3 & 22.8 \\
Moderate-intensity exercise & 6 & 18.1 & 23.7 \\
High-intensity exercise & 5 & 15.0 & 21.8 \\
\hline
\end{tabular}

No significant difference was found among groups (analysis of variance). $(p=0.414)$ (Table 2).

\section{Graafian follicles}

The Graafian follicle count was higher in the groups that received exercise training, but there were no significant differences among the groups ( $p=0.714$ ) (Table 2).

\section{Discussion}

In this study, no significant differences among groups were found in the increase in mice body weight before and after treatment. The greatest increase in body weight occurred in the control group, and the lowest increase in the moderate-intensity group. Regular exercise is an important component of supporting the long-term reduction of overweight. Changes in body weight occur as a result of compensatory mechanisms by the body. Increased energy expenditure due to exercise also increases food intake, as mediated by the hormone leptin. Low leptin levels can increase the risk of infertility due to increased body weight $[1,15]$. Leptin levels tend to be stable when there is a balance between energy expenditure and energy intake.

During exercise, there is a reciprocal relationship between the balance of energy and the hypothalamus-pituitary-gonadal axis, triggering proper development of ovarian follicles $[15,16]$. The present study showed a tendency for the number of follicles to be higher in the treatment groups than in the control group. This aligns with the findings of Kiranmayee et al. [17] regarding the effects of moderate-intensity exercise on markers of ovarian reserve in women with normal weight. The average antral follicular count was also higher in the exercise groups, although the difference was not significant. The study also revealed that moderate exercise had a positive influence on ovarian reserve profile, as the number of apoptotic follicles was lower in the groups that underwent exercise training. This implies that exercise improves the maturation of follicles, with positive impacts on women's fertility [18].

This study found that moderate-intensity exercise had better effects on the development of ovarian follicles than mild or high-inten-

Table 2. The average number of total follicles and each follicle type

\begin{tabular}{|c|c|c|c|c|c|c|}
\hline \multirow{2}{*}{ Group } & \multirow{2}{*}{$\mathrm{n}$} & \multicolumn{5}{|c|}{ Follicle } \\
\hline & & Total & Primary & Secondary & Tertiary & Graafian \\
\hline Control & 4 & $26 \pm 7.9^{\text {a) }}$ & $15.3 \pm 6.2$ & $4.3 \pm 1.3$ & $4.8 \pm 2.1$ & $1.8 \pm 0.5$ \\
\hline Mild-intensity exercise & 4 & $19 \pm 5.5^{\mathrm{a})}$ & $7.8 \pm 4.9$ & $5 \pm 1.4$ & $5 \pm 3.6$ & $1.3 \pm 0.5$ \\
\hline Moderate-intensity exercise & 6 & $42.7 \pm 16.4^{b)}$ & $25.8 \pm 12.4$ & $8 \pm 2.7$ & $7.3 \pm 3.1$ & $1.5 \pm 1.5$ \\
\hline High-intensity exercise & 5 & $29.6 \pm 8.3^{\mathrm{a}, \mathrm{b})}$ & $16.6 \pm 7$ & $6.4 \pm 2.9$ & $5.4 \pm 1.1$ & $1.2 \pm 0.8$ \\
\hline
\end{tabular}

Values are presented as mean \pm standard deviation. Data were analyzed with analysis of variance and the post-hoc least significant difference test, except for the data on Graafian follicles (Kruskal-Wallis test).

a),b) Different superscripts showed significant differences $(p<0.05)$. 
sity exercise. Generally, exercise may inhibit the reproductive axis through direct or indirect inhibition of GnRH by corticotropin-releasing hormone, $\beta$-endorphin, and glucocorticoids, thereby reducing the secretion of luteinizing hormone (LH) and FSH, as well as the hormonal secretion of the gonads, and rendering the target tissues of sex steroids resistant to these hormones [19]. However, some studies have reported that exercise of various intensities had different effects on ovarian follicle. In addition to our study, Kiranmayee et al. [17] conducted a study on 162 women at ages between 19 and 42 and found that moderate-intensity physical activity was associated with higher levels of anti-Müllerian hormone and FSH. Physical activity may influence the neurohumoral modulation of the metabolic pathways involved in energy metabolism and reproduction [20]. Moderate exercise may increase the responsiveness and sensitivity of the follicle to FSH and LH with a concomitant improvement in ovulatory status in young women [21]. Therefore, follicles developed to a greater extent in response to moderate-intensity exercise than in response to mild or high-intensity exercise.

The acute response of cortisol, which is associated with increased adrenocorticotropic hormone concentrations, was greater during high-intensity exercise than during moderate-intensity exercise [22]. Increased cortisol concentrations can suppress the synthesis of steroid hormones and can even impair the preovulatory LH surge, resulting in ovulation failure. Suppression of the LH surge can impair follicle development and estrogen synthesis, as well as increasing the formation of follicular atresia [23]. An increase in the plasma cortisol concentration initiates negative feedback of estrogen, which then suppresses the frequency or amplitude of $\mathrm{GnRH}$, reducing the secretion of gonadotropins, ultimately inhibiting ovulation and triggering the formation of small ovarian cysts [24]. In contrast, low-intensity exercises may lead to a decrease in blood cortisol levels by increasing clearance [25]. Therefore, follicular development is less disturbed by mild-intensity exercise than by high-intensity exercise. However, mild-intensity exercise was still associated with less favorable follicular development than moderate-intensity exercise, which may be because moderate-intensity exercise elicits a better response to FSH and LH [21].

Primary follicles are independent of gonadotropins and therefore do not depend on FSH [26]. Consequently, reduced FSH levels due to physical exercise will not affect primary follicles. In this study, the number of primary follicles was significantly higher in the exercise groups than in the control group. This result aligns with those reported by Kelley et al. [9], who investigated outcomes in mares in response to a 3-week running intervention and showed significant differences in the number of small-diameter (primary) follicles compared to the control group. Environmental factors, including nutrition, also have a strong influence on the development of primary fol- licles. Primordial and primary follicles require a considerable amount of nutrients to continue development; therefore, the nutrients available affect the development of these follicles $[27,28]$. It can be assumed that there is a balance between the nutrient intake and the energy expenditure of physical exercise. Good nutrition can increase the number of developing primary follicles.

The folliculogenesis stage, in which primary follicles become secondary follicles, is the most common stage at which follicles undergo apoptosis. This is because these follicles are mainly controlled by intrafollicular factors such as growth factors, cytokines, and gonadal steroids, and have not been influenced by FSH. This stage reflects a transitional state from the gonadotropin-independent phase to the gonadotropin-dependent phase [29]. In this study, fewer secondary than primary follicles were observed, because only high-quality follicles were selected for the subsequent stage. Seyed Saadat et al. [4] investigated the effects of forced swimming training with cold and fresh water for 2 weeks on ovarian and uterine parameters in mice, and found fewer secondary follicles in the exercise group than in control group. In contrast, the present study observed higher numbers of secondary follicles in the exercise groups than in the control groups, which may reflect differences in the increase in reactive oxygen species (ROS) in response in different intensities and durations of exercise. ROS play a regulatory role in oocyte maturation, folliculogenesis, ovarian steroidogenesis, and luteolysis. A balance between ROS and antioxidant enzymes in the ovary can protect oocytes [7,3032].

Tertiary follicles and Graafian follicles are gonadotropin-dependent stages. Hence, their development depends strongly on the production of gonadal hormones such as FSH. Exercise is known to trigger disordered GnRH pulses that can interfere with FSH levels. Folliculogenesis is not only related to the growth of granulosa cells, but also related to the intracrine, paracrine, and autocrine systems. Tertiary and Graafian follicles have more potent defense mechanisms against oxidative stress than primary and secondary follicles. Therefore, even if FSH deficiency occurs, these follicles can still survive until maturation [30,32,33]. This study revealed that the number of tertiary and Graafian follicles tended to increase, although no significant between-group differences were found. This result does not align with the findings of Seyed Saadat et al. [4], who reported significant differences in tertiary and Graafian follicles in mice in response to different water temperatures when swimming. Swimming in cold water (or other types of cold exposure) in mice can affect the hypothalamic-pituitary-adrenal axis, inhibiting the release of FSH and thereby inducing estrus cycle irregularities and some alterations in the morphology of the ovary [34,35]. As a result, our study, which had a longer duration of swimming (4 weeks) and a longer swimming time per session than Seyed Saadat's study [4], reported a different pat- 
tern of ovarian follicles.

Physiologically, the number of follicles decreases from the primary to the Graafian stage, until the follicles become mature, because only follicles that are well developed and highly sensitive to gonadotropins will persist $[18,33]$. In this study, the decline did not differ significantly among groups, although different patterns were found in each group. The treatment groups showed more favorable development of follicles from the primary to the Graafian stage, with the highest numbers of follicles found in response to moderate-intensity exercise.

\section{Conflict of interest}

No potential conflict of interest relevant to this article was reported.

\section{Acknowledgments}

The authors thank all team members at the embryology laboratory for their technical assistance during the research, the team members at the pathology department for the histological analysis, and Bilqisthi Ari Putra at the pathology department as a second observer for calculation of follicle count (Faculty of Veterinary Medicine, Universitas Airlangga, Indonesia).

\section{ORCID}

Fitri Kurnia Rahayu

Sri Ratna Dwiningsih

Ashon Sa'adi

Lilik Herawati https://orcid.org/0000-0002-8213-3012 https://orcid.org/0000-0002-3952-2020 https://orcid.org/0000-0003-2682-3139 https://orcid.org/0000-0002-8014-6952

\section{Author contributions}

Conceptualization: LH, FKR. Data curation: FKR, LH, SRD. Formal analysis: FKR, LH. Funding acquisition: LH. Methodology: all authors. Project administration: LH, SRD. Visualization: FKR. Writing-original draft: FKR, LH. Writing-review \& editing: LH, SRD, AS.

\section{References}

1. Warren MP, Perlroth NE. The effects of intense exercise on the female reproductive system. J Endocrinol 2001;170:3-11.

2. Warren MP, Shantha S. The female athlete. Baillieres Best Pract Res Clin Endocrinol Metab 2000;14:37-53.

3. Hestiantoro A, Soebijanto S, Wiweko B, Pratama G, Yusuf D. Consensus on infertility treatment. Himpunan Endokrinologi Repro- duksi dan Fertilitas Indonesia (HIFERI), Perhimpunan Fertilisasi In Vitro Indonesia (PERFITRI), Ikatan Ahli Urologi Indonesia (IAUI), Dan Perkumpulan Obstetri Dan Ginekologi Indonesia (POGI); 2013.

4. Seyed Saadat SN, Mohammadghasemi F, Ebrahimi H, Rafati Sajedi H, Chatrnour G. Ovarian and uterine alterations following forced swimming: an immunohistochemical study. Int J Reprod Biomed 2016;14:629-36.

5. Joo MH, Maehata E, Adachi T, Ishida A, Murai F, Mesaki N. The relationship between exercise-induced oxidative stress and the menstrual cycle. Eur J Appl Physiol 2004;93:82-6.

6. Smith AJ, Phipps WR, Thomas W, Schmitz KH, Kurzer MS. The effects of aerobic exercise on estrogen metabolism in healthy premenopausal women. Cancer Epidemiol Biomarkers Prev 2013; 22:756-64.

7. Kawamura T, Muraoka I. Exercise-induced oxidative stress and the effects of antioxidant intake from a physiological viewpoint. Antioxidants (Basel) 2018;7:119.

8. Shi L, Zhang J, Lai Z, Tian Y, Fang L, Wu M, et al. Long-term moderate oxidative stress decreased ovarian reproductive function by reducing follicle quality and progesterone production. PLoS One 2016;11:e0162194.

9. Kelley DE, Gibbons JR, Smith R, Vernon KL, Pratt-Phillip SE, Mortensen CJ. Exercise affects both ovarian follicular dynamics and hormone concentrations in mares. Theriogenology 2011; 76:615-22.

10. Bompa T, Carrera M. Theory and methodology of training: general perspectives. In: Blumenstein B, Lidor R, Tenenbaum G, editors. Psychology of sport training: perspectives on sport and exercise psychology. Oxford: Meyer \& Meyer Sport; 2007. p. 19-39.

11. Gobatto CA, de Mello MA, Sibuya CY, de Azevedo JR, dos Santos LA, Kokubun E. Maximal lactate steady state in rats submitted to swimming exercise. Comp Biochem Physiol A Mol Integr Physiol 2001;130:21-7.

12. Herawati L, Irwadi I, Sari GM, editors. Increase in sugar-transporting protein (Glut4) with a high carbohydrate diet and regular physical exercise. Proceedings of IAIFI XVI National Congress, Symposium, National Seminar, and XXIV Workshop ": holistic interaction between organisms and the environment for a better quality of life: food security, health and sports achievement; 2015 Oct 29-31; Padang, Indonesia. Padang: IAIFI Cabang Sumatera Barat; 2015.

13. Wasinski F, Bacurau RF, Moraes MR, Haro AS, Moraes-Vieira PM, Estrela GR, et al. Exercise and caloric restriction alter the immune system of mice submitted to a high-fat diet. Mediators Inflamm 2013;2013:395672.

14. Myers M, Britt KL, Wreford NG, Ebling FJ, Kerr JB. Methods for quantifying follicular numbers within the mouse ovary. Repro- 
duction 2004;127:569-80.

15. Gao Q, Horvath TL. Cross-talk between estrogen and leptin signaling in the hypothalamus. Am J Physiol Endocrinol Metab 2008; 294:E817-26.

16. Lee K, Joo J, Kim S, Lee S. Effect of regular exercise on reproductive function of aged female mice. Fertil Steril 2016;106(3_Suppl): e119.

17. Kiranmayee D, Praveena T, Himabindu Y, Sriharibabu M, Kavya K, Mahalakshmi M. The effect of moderate physical activity on ovarian reserve markers in reproductive age women below and above 30 years. J Hum Reprod Sci 2017;10:44-8.

18. Pramesti NA, Restiadi TI, Yudhana A. The effect of soybean extract (Glycine max) on total growth of ovarian follicles in mice (Mus musculus). J Med Vet 2018;1:120-7.

19. Uadia PO, Nwokolo CC, Arainru AE, Agwubike EO, Akpata CB. Effect of physical and flexibility exercise on certain hormones and fasting blood sugar of some young Nigerian adults. Trop J Pharm Res 2017;16:245-50.

20. Ronkainen $H$, Pakarinen A, Kirkinen P, Kauppila A. Physical exercise-induced changes and season-associated differences in the pituitary-ovarian function of runners and joggers. J Clin Endocrinol Metab 1985;60:416-22.

21. Ruder EH, Hartman TJ, Blumberg J, Goldman MB. Oxidative stress and antioxidants: exposure and impact on female fertility. Hum Reprod Update 2008;14:345-57.

22. Raastad T, Bjoro T, Hallen J. Hormonal responses to high- and moderate-intensity strength exercise. Eur J Appl Physiol 2000; $82: 121-8$

23. Zhu HS, Qian Z, Liu HL, Bao ED. ACTH-induced stress in weaned sows impairs LH receptor expression and steroidogenesis capacity in the ovary. Reprod Biol Endocrinol 2016;14:80.

24. Yuan HJ, Han X, He N, Wang GL, Gong S, Lin J, et al. Glucocorticoids impair oocyte developmental potential by triggering apoptosis of ovarian cells via activating the Fas system. Sci Rep 2016;6:
24036.

25. Hill EE, Zack E, Battaglini C, Viru M, Viru A, Hackney AC. Exercise and circulating cortisol levels: the intensity threshold effect. J Endocrinol Invest 2008;31:587-91.

26. Dharma SJ, Modi DN, Nandedkar TD. Gene expression profiling during early folliculogenesis in the mouse ovary. Fertil Steril 2009; 91(5 Suppl):2025-36.

27. Ramadhani SA, Supriatna I, Karja NW, Winarto A. Folliculogenesis control in ovarian with the cottonseed extract. J Sain Vet 2017; $35: 71-80$.

28. Williams NI, Ruffing KM. The menstrual cycle and the exercising female. In: Forsyth J, Roberts CM, editors. The exercising female. London: Routledge; 2019. p. 19-29.

29. Orisaka M, Tajima K, Tsang BK, Kotsuji F. Oocyte-granulosa-theca cell interactions during preantral follicular development. J Ovarian Res 2009;2:9.

30. Agarwal A, Gupta S, Sharma RK. Role of oxidative stress in female reproduction. Reprod Biol Endocrinol 2005;3:28.

31. Zhang JQ, Shen M, Zhu CC, Yu FX, Liu ZQ, Ally N, et al. 3-Nitropropionic acid induces ovarian oxidative stress and impairs follicle in mouse. PLoS One 2014;9:e86589.

32. Agarwal A, Aponte-Mellado A, Premkumar BJ, Shaman A, Gupta S. The effects of oxidative stress on female reproduction: a review. Reprod Biol Endocrinol 2012;10:49.

33. Cho GJ, Han SW, Shin JH, Kim T. Effects of intensive training on menstrual function and certain serum hormones and peptides related to the female reproductive system. Medicine (Baltimore) 2017;96:e6876.

34. Lafrance M, Roussy G, Belleville K, Maeno H, Beaudet N, Wada K, et al. Involvement of NTS2 receptors in stress-induced analgesia. Neuroscience 2010;166:639-52.

35. Xu T, Li X, Yang L, Zhang Y, Zhang L, Guo Z, et al. Impact of cold exposure on the reproductive function in female rats. Biomed Res Int 2018;2018:3674906. 